www.conferenceie.ase.ro

\title{
INFORMATICS METHODS TO INCLUDE LIMIT CONDITIONS INTO AUTOMATED CAPITAL INVESTMENT SOFTWARE SYSTEMS
}

\author{
Cristian PĂUNA \\ Bucharest University of Economic Studies, Romania \\ cristian.pauna@ie.ase.ro \\ Ion LUNGU \\ Bucharest University of Economic Studies, Romania \\ ion.lungu@ie.ase.ro
}

\begin{abstract}
Using automated capital investment software systems is a common task today. At the beginning of the third millennium, modern investors are using artificial intelligence resources and methods to find the best investment opportunities on capital markets and to process the trading orders. One of the most important aspects of this activity, besides the buying and selling decisions, is to stay away from the market risk in specific conditions. For this purpose, in the current doctoral research, the notion of limit conditions in capital markets was introduced by the authors. On the high price volatility markets, when the economic or geopolitical background is changing fast, real-time decisions for earlier investment closing, or filtering decision not to open new positions in specific market states, will contribute together to the risk reduction and will provide a higher capital efficiency a the long time run. In the real-time investment software systems, the limit conditions method's implementation presumes particular aspects in order not to introduce additional time delays for the trading orders. This paper will present the way how to include additional limit conditions procedures into automated algorithmic trading software systems. It was found that any investment strategy can be improved by using the limit conditions methods presented in this paper. Based on particular data-mining methods applied to real-time price series of any market, these methods can be automated and included in any capital investment informatics systems in order to improve the results and to reduce the allocated capital risk.
\end{abstract}

Keywords: Capital investment informatics systems, limit conditions, data-mining, real-time price series, capital efficiency improvement.

JEL classification: M15, O16, G23

DOI: $10.24818 / \mathrm{ie} 2020.04 .01$

\section{Introduction}

One of the most interesting consequences of the global scale usage of electronic computers in the capital investment activity on financial markets is that new research and developing directions have arisen in the first decades of the third millennium. The automatic price processing of the stock exchange quotes allows us today to build automated investment software. With these informatics systems, the price evolution is analyzed using real-time datamining methods, the investment decisions are made almost instantly through advanced prediction algorithms, and the buying and selling orders are built and also sent automatically to the brokerage informatics systems. The final and only purpose is to make a profit.

The design and implementation of automated investment informatics systems are activities with a high complexity degree. This paper is a part of doctoral research conducted by the authors in the last years with the subject of modern methodologies for business intelligence 
systems design. Methodological approaches about the conceptual design of automated investment systems can be found in [1] and [2].

The investment informatics system receives real-time data streams from brokerage companies. It includes specific extract, transformation, and loading procedures in order to store all the information into the data warehouse. The data streams contain the price quotes of any stock exchange analyzed and also the data about the capital and available liquidity in each investment account managed.

The data quotes evolution of each capital market is analyzed using data-mining methods specially adapted for time price series. Theoretically, any trading or investment strategy can be adapted to be used in automated capital investment systems. Reliable strategies to build datamining models for stock markets can be found in [3], [4], [5], and [6].

For the currency and commodity markets, reliable trading models that can be automated and included in investment software can be found in [7], [8], and [9]. Original data-mining methods, especially designed and optimized for automated capital investment software, can be found in [10]-[19]. Investment signals are built using all of these models by analyzing the realtime price series. Different models can be used for risk and capital management procedures. One of the most reliable methods is presented in [20].

In the current research was found that automation of investment models is not enough to obtain a low-risk investment. In special market conditions, the investment signals must be filtered not to open trading positions on the high-risk environment. Moreover, once the economic background can be changed after initiating investment entries, particular limit conditions will be used for the early closing of current investments in particular market states. This paper will present a way to incorporate limit conditions procedures into automated investment systems. The article includes the most important limit conditions methods used in this research to reduce capital exposure and to increase investment efficiency.

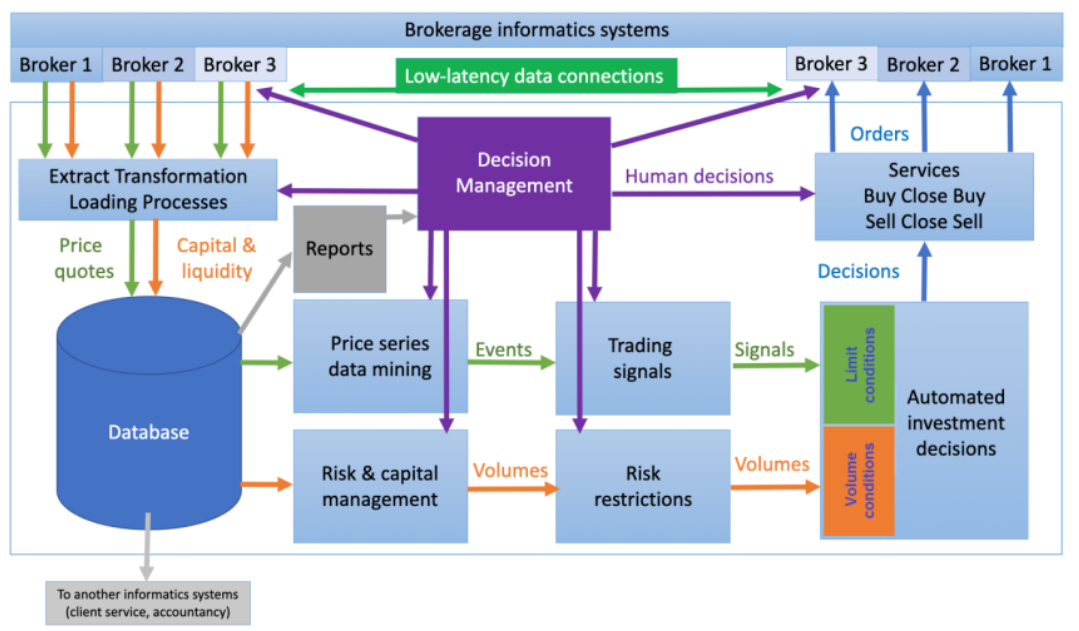

Figure 1. Conceptual design of automated capital investment system.

\section{Limit conditions in automated capital investment systems}

In figure 1, it is presented the conceptual design scheme of an automated capital investment system. As can be seen, the data processing procedures include two individual data streams. The first one transforms the time price series into investment signals using data-mining methods. The second one analyzes the capital and available liquidity in each account. The investment signals and the computed volumes streams are input data for the automated investment decision module. This component will build the trading decision for each managed 
account and will generate informatics services that are sent to the brokerage company to be transformed into order and to be executed on the markets.

The design factor of all components in the automated investment software systems is the time delay included by each procedure or module into the data stream. This factor is critical in realtime data processing software. Moreover, into the investment systems, the time delay is essential to be as lower possible. If the delay between the price change and the order received by the brokerage company is too high, the price orders can be much different from the market price. This fact can conduct to the order deny or can be a significant factor for the obtained capital efficiency. Delays higher than 200 milliseconds are considered too high in today's investment informatics systems.

Data processing in the limit conditions procedures is different and separately than the datamining procedures used to generate the events and the investment signals. For example, a system can use an investment strategy that analyzes the price evolution of a 4-hour real-time price series. This strategy can find a trading opportunity in a specific market. At the same time, a limit condition procedure applied on a daily or weekly timeframe on the same market can find a boundary or an overbought price. This condition will cancel the investment signal or will close the already opened positions in that market. This research called all these conditions as limit conditions once they are all figured as true when a specific mathematical function overtakes a specified limit value.

This research has found that a parallel computational data flow for the limit conditions procedures will decrease the time delay significantly. The restrictions are subject to parallel data processes that are computed at the same time as the data-mining procedures. In this way, when a signal arrives, the restrictive conditions are already made and can be applied.

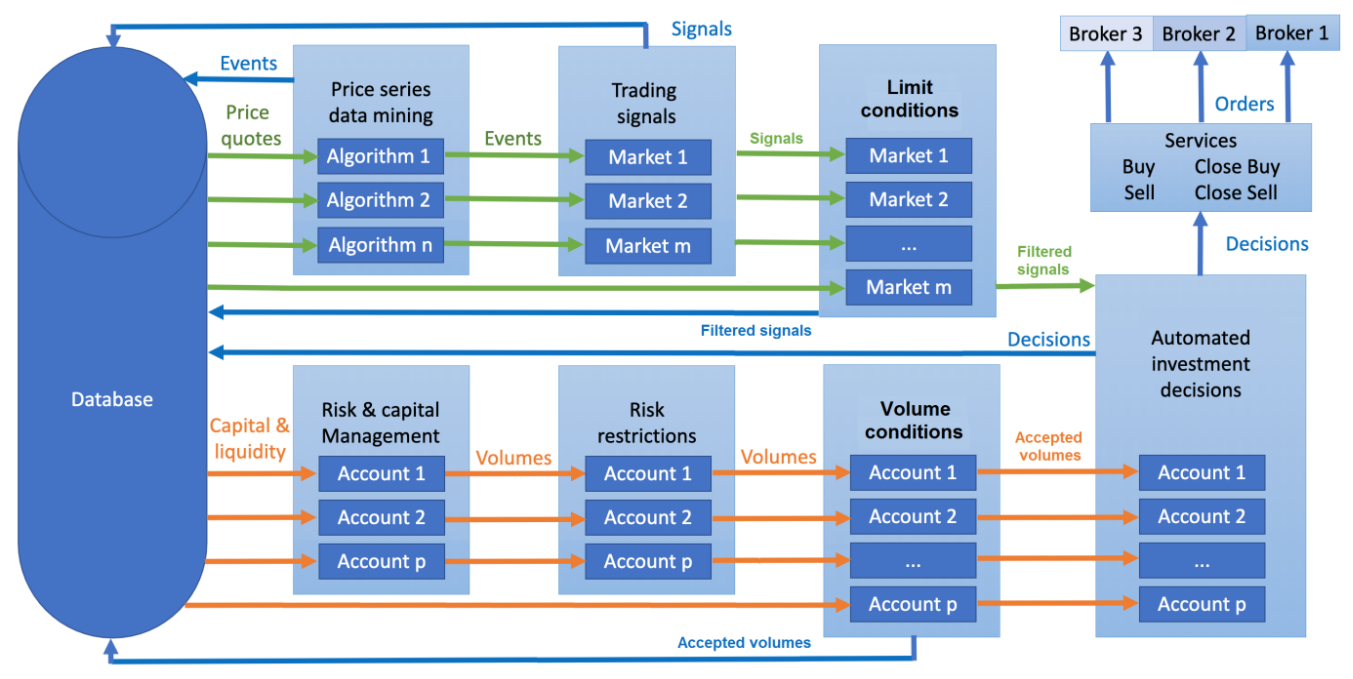

Figure 2. Events-signals-decision-services data flow in modern capital investment informatics systems.

In figure 2, it is revealed the data flow of a modern capital investment informatics system. The volume conditions are referring mainly to the limitation of the quantity of the traded equities depending on the available capital in the investment account, on the leveraged used, on the already opened investment positions, all in strict relation with the capital exposure level approved by the investor. All of these are not subject to this paper but can be fit together using more considerations included in [20].

The limit conditions procedures will analyze different market factors and will cancel trading signals if specific conditions are met. Moreover, the limit conditions can be source for closing 
services and orders send into the brokerage system in order to close the already made investments, with the purpose to optimize the profitability and to reduce the capital risk. The most important limit conditions identified in the current research are presented below.

\section{Don't buy near maximum price levels.}

One of the essential limit conditions types is related to the principle to not buy near the maximal price levels. It is well known that markets can evolve for a long time into a range situated near local or global maximal levels. Any investment initiated here can produce losses once the market passes the maximal point and decreases in the next period of time. Until this moment, important trading or investment strategies can generate signals when they are applied on a lower timeframe. Usually, these signals are good entries on the market but not in particular states, when the market is approaching a maximal value.

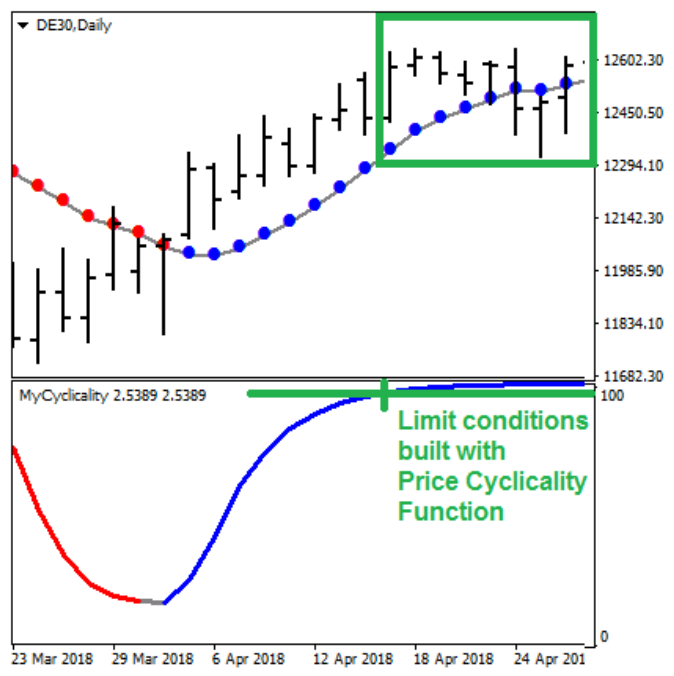

Figure 3. Limit conditions with PCY Function

This research has identified more limit conditions methods to filter these cases. To exemplify, in figure 3 was drawn the method to build limit conditions using the Price Cyclicality Function $(P C Y)$ introduced in [19]. No new investments trades will be opened if the $P C Y$ function overtakes a specified limit value:

$$
\text { NoOpenBuy }=\left(P C Y_{D 1}>\xi\right)
$$

Already opened investment positions in the current market will be closed if the $P C Y$ function exceeds a particular value:

$$
\text { CloseBuy }=\left(P C Y_{D 1}>\lambda\right)
$$

Similar limit conditions can be made using the Inverse Fisher RSI (IFR) introduced in [16]:

$$
\begin{gathered}
\text { NoOpenBuy }=\left(I F R_{D 1}>\varphi\right) \\
\text { CloseBuy }=\left(I F R_{D 1}>\psi\right)
\end{gathered}
$$

A particular type of limit conditions to avoid trading near-maximal price levels can be made limiting the distance between the current price level and an adequate price trend line. Very good results are obtained using the Price Prediction Line $(P P L)$ introduced in [11] and Trigonometric Price Line (TPL) introduced in [10]. The limit conditions are made using:

$$
\begin{aligned}
& \text { NoOpenBuy }=\left(p-P P L_{D 1}>\delta\right) \vee\left(p-T P L_{D 1}>\gamma\right) \\
& \text { CloseBuy }=\left(p-P P L_{D 1}>\alpha\right) \vee\left(p-T P L_{D 1}>\beta\right)
\end{aligned}
$$


where $p$ is the current price level. In all formulas above, $\alpha, \beta, \xi, \lambda, \gamma, \delta, \varphi$, and $\psi$ and $\varepsilon, \omega, \pi$, and $\mu$ in below formulas, are functional parameters that will be optimized for each market using the historical time price series and statistical methods to reduce capital exposure and to optimize the obtained profit. All these parameters are also subjects to an individual machinelearning procedure that will be repeated all the time in order to use the optimal functional parameters depending on the last time market behavior changes.

\section{Don't trade on non significant price movements}

Another type of limit condition is referring to those time intervals when the market does not make a significant price movement. On low volatility market conditions, the profit is small, and the capital efficiency is reduced by swap commissions added over time. The current research has identified a function that can be used to build limit conditions to avoid these cases. Using Silent Market Indicator (SMI) introduced in [21], we can use:

$$
\text { NoOpenBuy }=\left(S M I_{D 1}<\varepsilon\right) \text { and CloseBuy }=\left(S M I_{D 1}>\varpi\right)
$$

\section{Don't invest in low price grow probability}

One of the most critical criteria in investment is to buy when the chance for a price increase is high. Much better profitability will be obtained if we do not invest when the price growth probability is low. This research has identified a reliable function to estimate the price growth probability. Using the Price Probability predictor $(P P P)$ introduced in [22], the limit conditions can be build using the next formulas:

$$
\begin{aligned}
& \text { NoOpenBuy }=\left(P P P_{D 1(i)}>P P P_{D 1(i-1)}\right) \wedge\left(P P P_{D 1(i)}>\pi\right) \\
& \text { CloseBuy }=\left(P P P_{D 1(i)}<P P P_{D 1(i-1)}\right) \vee\left(P P P_{D 1(i)}<\mu\right)
\end{aligned}
$$

where the index (i) denotes the current day price interval, and (i-1) the previous day interval.

\section{Results and conclusions}

Two cases were studied to prove the advantages of using the limit conditions presented. It was made a simulation of investment between 01.01.2017 and 31.12.2019 using DaxTrader automated software system (https://pauna.biz/daxtrader), with and without limit conditions (1)(9). Without the limit condition, a risk to reward ratio (RRR) of 1:3.28 per year was obtained. With all the limit conditions presented, RRR obtained has a value of 1:5.01. This is an efficiency growth with $52.47 \%$. Besides, the longest investment position without limit conditions lasted 3.102 hours. In the case with limit conditions, the most extended investment period was only 345 hours. This shows us a significant investment improvement activity. In the time saved using the limit conditions, the capital can be involved in other investments, which is an additional efficiency factor. The time delay obtained between the price change and the order receiving in the brokerage informatics system is between 38 and 120 milliseconds. The general conclusion is that the methods presented to include limit conditions into automated investment systems are reliable, and can be used to increase capital efficiency.

\section{References.}

[1] C. Păuna, "Automated Trading Software. Design and Integration in Business Intelligence Systems.” Bucharest, Romania: Database System Journal. Volume IX, Issue 1/2018. ISSN: 2069-3230. Bucharest University of Economic Studies. Available at: http://dbjournal.ro

[2] C. Păuna, "Arbitrage Trading Systems for Cryptocurrencies. Design Principles and Server Architecture." Bucharest, Romania: Informatica Economica Journal. Volume 22, Issue 2/2018. ISSN: 1453-1305. DOI: 10.12948/issn14531305/22.2.2018.04

[3] L. Connors, C. Alvarez. "Short Term Trading Strategies That Work.”, US: TradingMarkets Publishing Group, New Jersey. 2009. ISBN: 978-0-0919239-0-1 
[4] L. Connors, C. Alvarez. "High Probability ETF Trading. 7 Professional Strategies to Improve Your ETF Trading". US: Connors Research. 2009. ISBN: 978-0-615-29741-5

[5] L. Connors, C. Sen C. "How Markets Really Work. A Quantitative Guide to Stock Market Behavior". US: Connors Research Group. 2004. ISBN 978-0-9755513-1-8

[6] L.A. Connors. "Best Trading Patterns. The Best of the Professional Traders Journal", US: M. Gordon Publishing Group. 1999. ISBN: 0-9650461-0-2

[7] K. Lien. "The Little Book of Currency Trading. How to Make Big Profits in the World of Forex." US: John Wiley \& Sons. 2011. ISBN: 978-0-470-77035-1

[8] K. Lien. "Day Trading and Swing Trading the Currency Market. Technical and Fundamental Strategies to Profit the Market.” John Wiley. 2009. ISBN: 978-0-470-377360

[9] G. Cheng. "7 Winning Strategies for Trading Forex. Real and actionable techniques for profiting from the currency markets." Hariman Trading. 2007. ISBN: 978-0-85719090-1

[10] C. Păuna. "Reliable signals and limit conditions using trigonometric interpolation for algorithmic capital investment." Alicante, Spain: 7th Business System Laboratory Internatinal Symposium 2020. University of Alicante, Spain. Available at: https://pauna.biz/ideas

[11] C. Păuna. "Price Prediction Line. Investment Signals and Limit Conditions Applied for the German Financial Market." International Journal of Computer and Information Engineering. Volume 13, No. 9/2019. World Academy of Science, Engineering and Technology. ISNI:0000000091950263. Available at: https://publications.waset.org

[12] C. Păuna. "Additional Limit Conditions for Breakout Trading Strategies." Bucharest, Romania: Informatica Economica Journal. Volume 23, Issue 2/2019. DOI: 10.12948/issn14531305/23.2.2019.03 Available at: http://revistaie.ase.ro

[13] C. Păuna. "A prediction model using the Price Cyclicality Function optimized for algorithmic trading in financial market." International Journal of Computer and Information engineering. Volume 13, No. 4/2019. Athens, Greece: World Academy of Science, Engineering and Technology: International Conference on Intelligent Information Systems ICIIS 2019. ISNI:0000000091950263. Available at: https://publications.waset.org

[14] Păuna C. "Data-mining methods on time prince series for algorithmic trading systems." Bucharest, Romania: Informatica Economica Journal. Volume 23, Issue 1/2019. ISSN: 1453-1305. DOI: 10.12948/issn14531305/ 23.1.2019.03. Available at: http://revistaie.ase.ro

[15] C. Păuna. "Low risk trading algorithm based on the price cyclicality function for capital markets." Bucharest, Romania: 13th International Conference on Business Excellence. FABIZ, Bucharest University of Economic Studies. DOI: 10.2478/mmcks-2019-0006

[16] C. Păuna. "Reliable Signals and Limit Conditions for Automated Trading Systems." Romania: Review of Economic and Business Studies. Volume XI, Issue 2/2018. ISSN: 1843-763X. DOI: 10.1515/rebs-2018-0070 Available at: http://rebs.feaa.uaic.ro

[17] C. Păuna. "Reliable Signals Based on Fisher Transform for Algorithmic Trading." Timișoara, Romania: Timișoara Journal of Economics and Business. Volume 11, Issue 1/2018 ISSN: 2286-0991. DOI: 10.2478/tjeb-2018-0006 Available at: https://tjeb.ro

[18] C. Păuna. "Smoothed Heikin-Ashi Algorithms Optimized for Automated Trading Systems", Graz, Austria: Proceeding of the 2nd International Scientific Conference on IT, Tourism, Economics, Management, and Agriculture, ITEMA 2018.

[19] C. Păuna, I. Lungu. "Price Cyclicality Model for financial markets. Reliable limit conditionsfor algorithmic trading", Bucharest, Romania: Economic Computation and 
Economic Cybernetics Studies and Research, Volume 52, Issue 4/2018. ISSN: 1842-3264. DOI: 10.24818/18423264/52.4.18.10 Available at http://ecocyb.ase.ro

[20] C. Păuna. "Capital and Risk Management for Automated Trading Systems." Iași, Romania: Proceedings of the 17th International Conference on Informatics in Economy, pp 183-188. Alexandru Ioan Cuza University. Available at: https://pauna.biz/ideas

[21] C. Păuna. "Silent Market Indicator. Methodology to avoid the risk in no significant price movements". Timișoara Jounal of Economics and Business. Volume 11, No. 2/2018. ISSN: 2286-0991. DOI: DOI: 10.2478/tjeb-2018-0009. Available at: https://www.tjeb.ro

[22] C. Păuna. "Price Probability Predictor. Capital investment assisted by a probability field" Bucharest, Romania: 14th International Conference on Business Excellence. FABIZ, Bucharest University of Economic Studies. 2020. 